\title{
Electron-transfer Reactions with Significant Changes in Structure. Unsymmetrical Crowded Ethylenes
}

\author{
Norma A. Macías-Ruvalcaba and Dennis H. Evans* \\ Department of Chemistry, University of Arizona, Tucson, AZ 85721 (USA) \\ Supporting Information
}

Examples of fits of simulation to experimental voltammograms for compounds 6 (Figures S1-S7), 7 (Figures S8-S14) and 8 (Figures S15-S19).

Figure caption for Figures S1-S7. Voltammogram (solid curve) of $2.40 \mathrm{mM}$ xanthylideneanthrone, 6. Symbols: simulation using the parameter values listed in Table 2. Temperature and scan rate shown in figure.

Figure caption for Figures S8-S14. Voltammogram (solid curve) of $2.00 \mathrm{mM}$ thioxanthylideneanthrone, 7. Symbols: simulation using the parameter values listed in Table 3. Temperature and scan rate shown in figure.

Figure caption for Figures S15-S19. Voltammogram (solid curve) of 2.17 mM 10(diphenylmethylene)anthrone, 8. Symbols: simulation using the parameter values listed in Table 5. Temperature and scan rate shown in figure. 


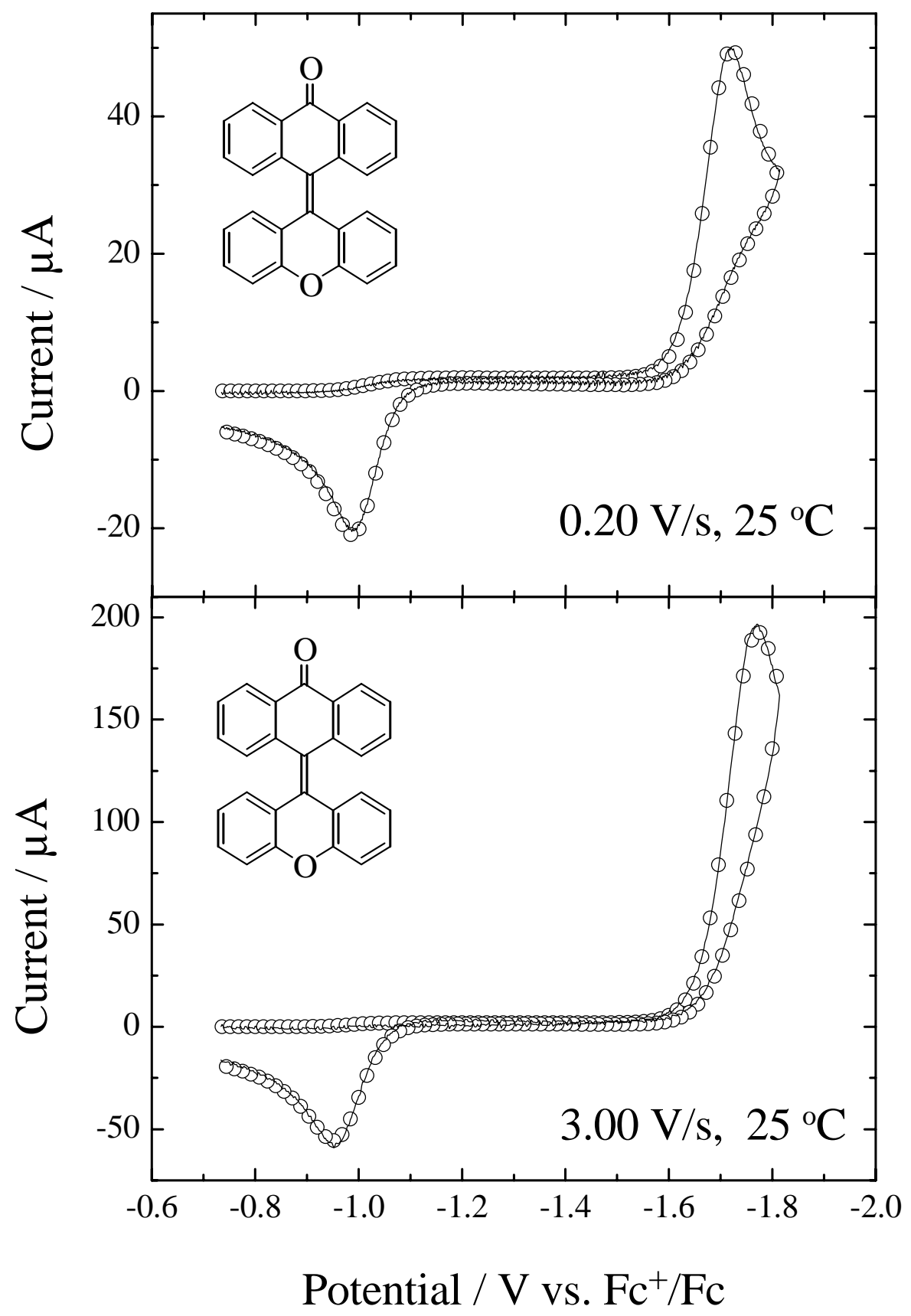

Figure S1 


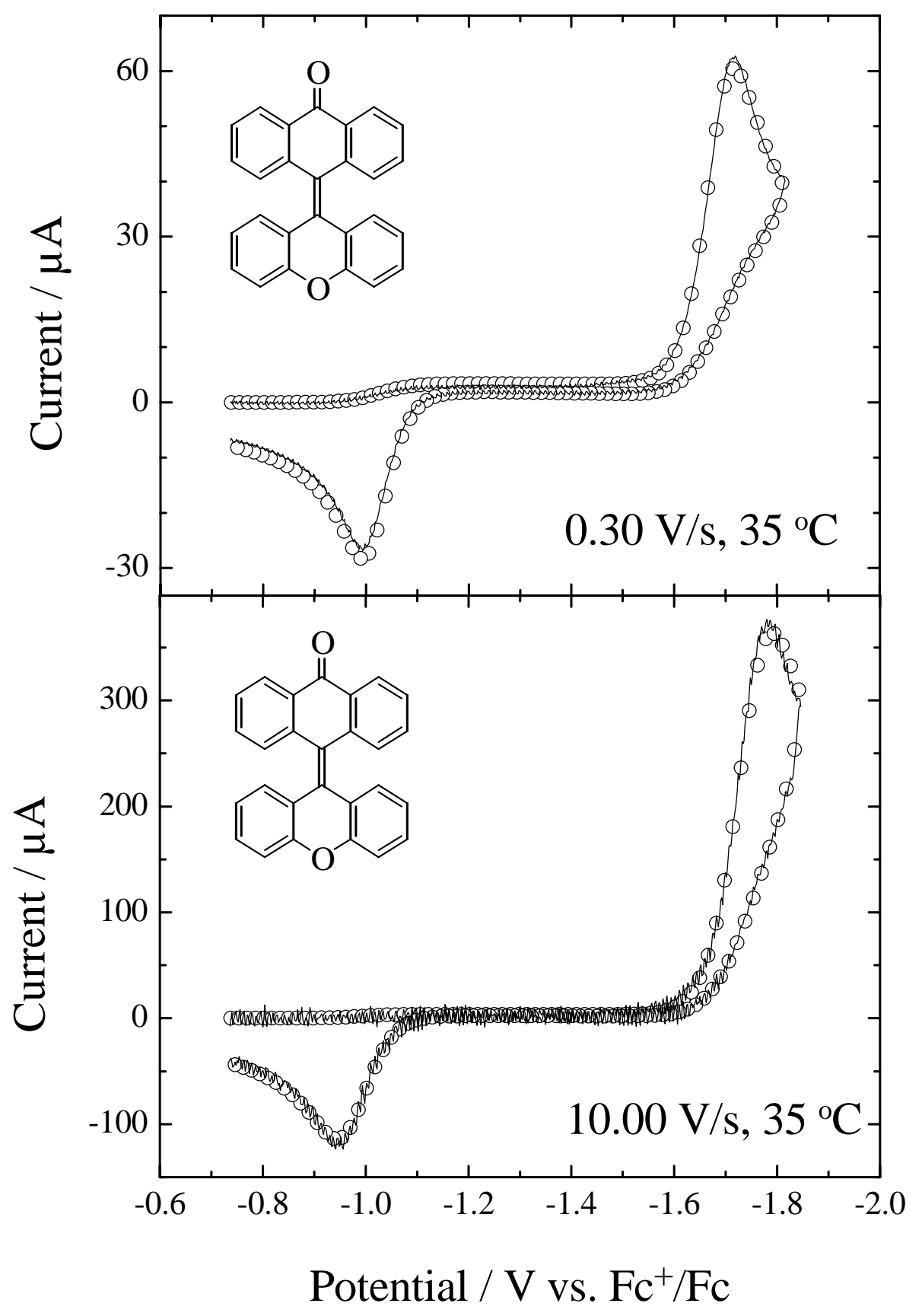

Figure S2 


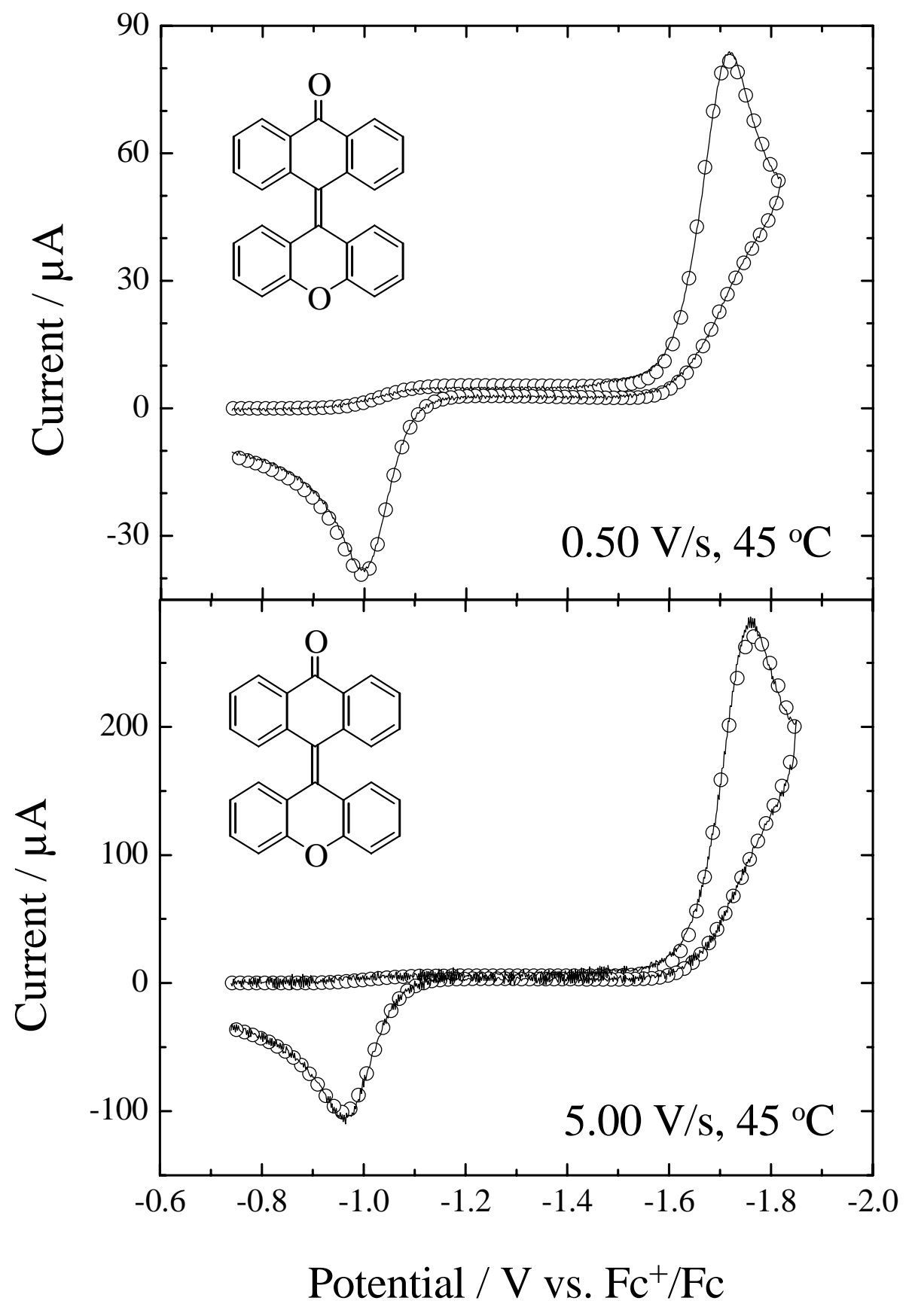

Figure S3 


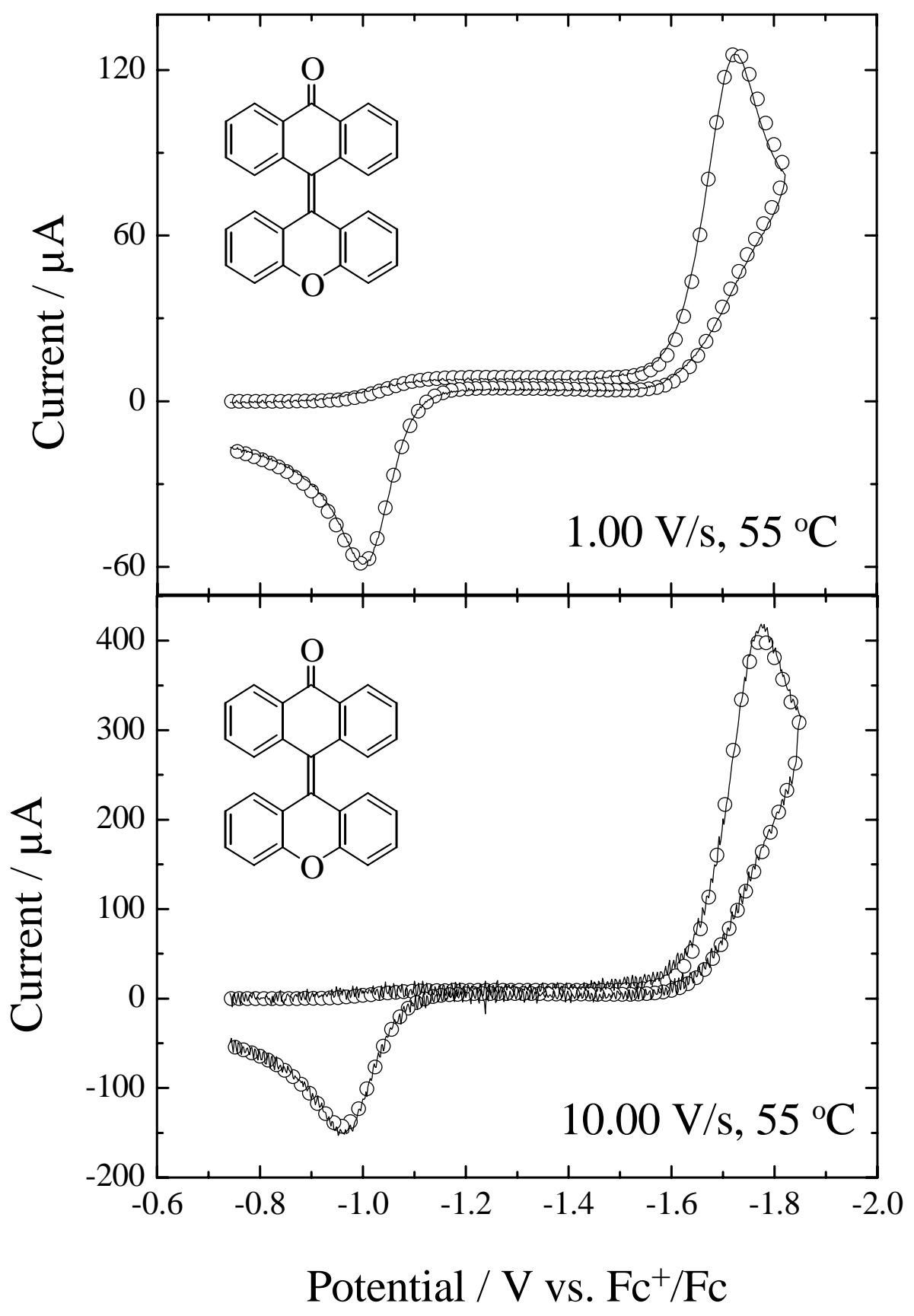

Figure S4 


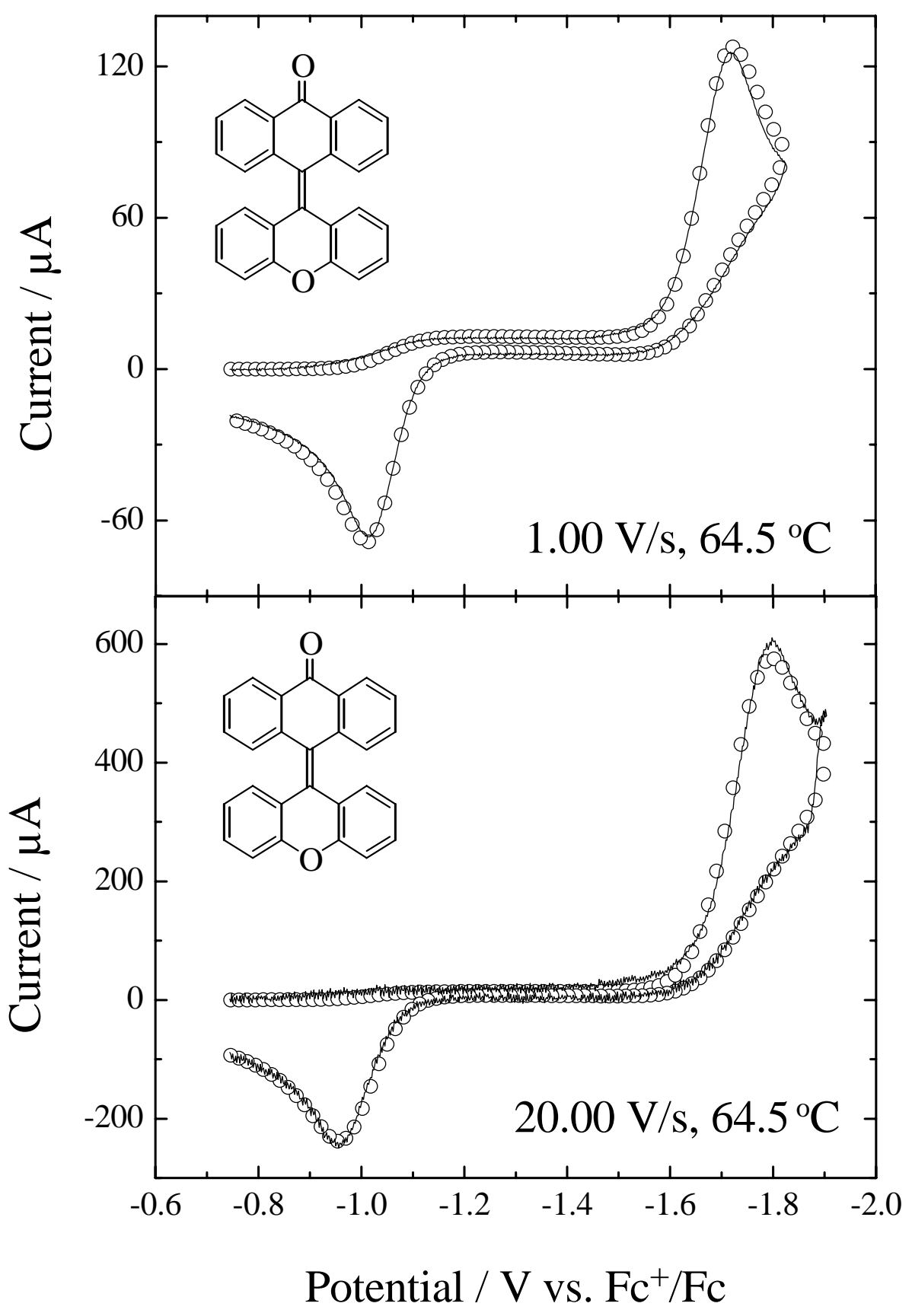

Figure S5 


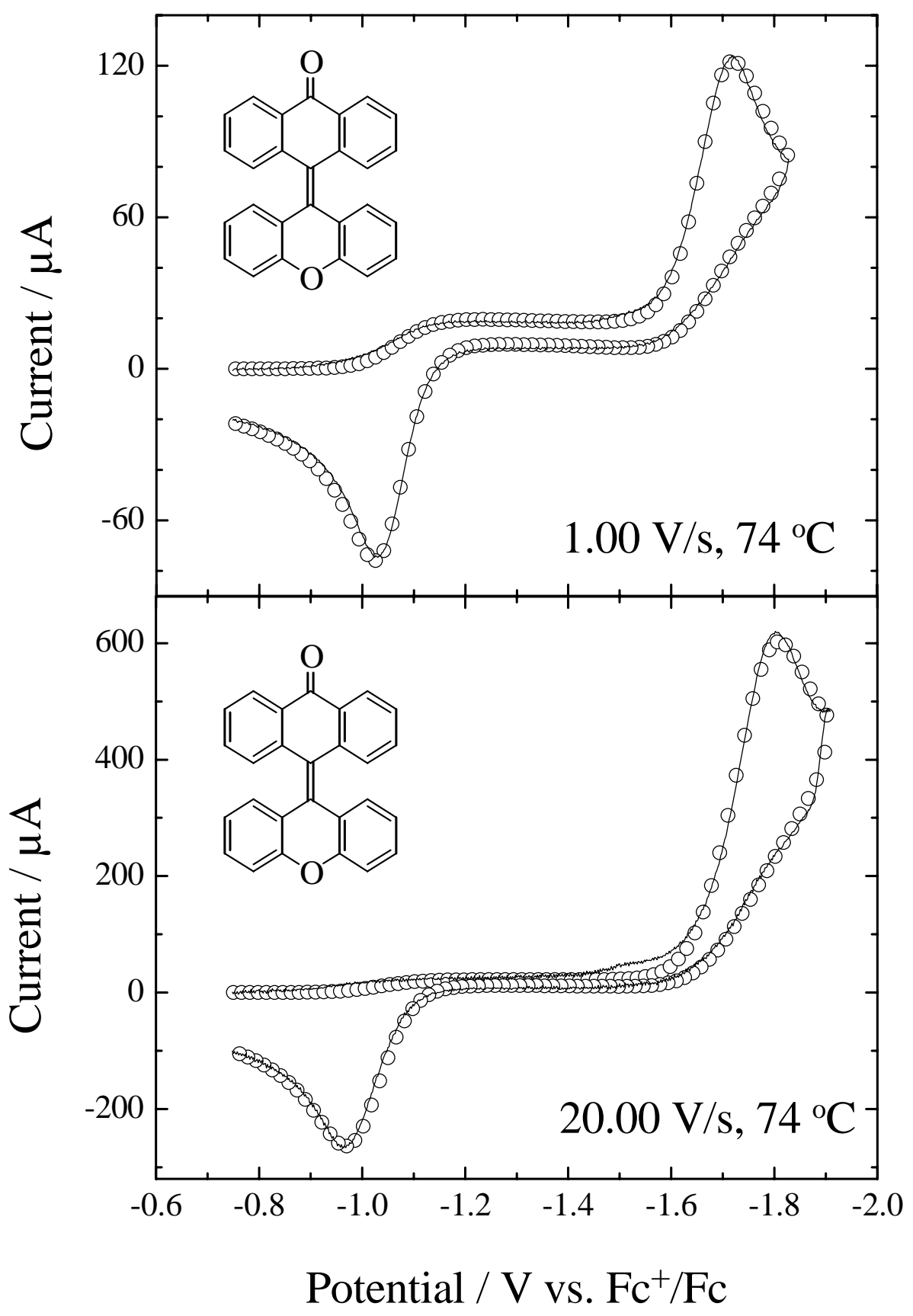

Figure S6 


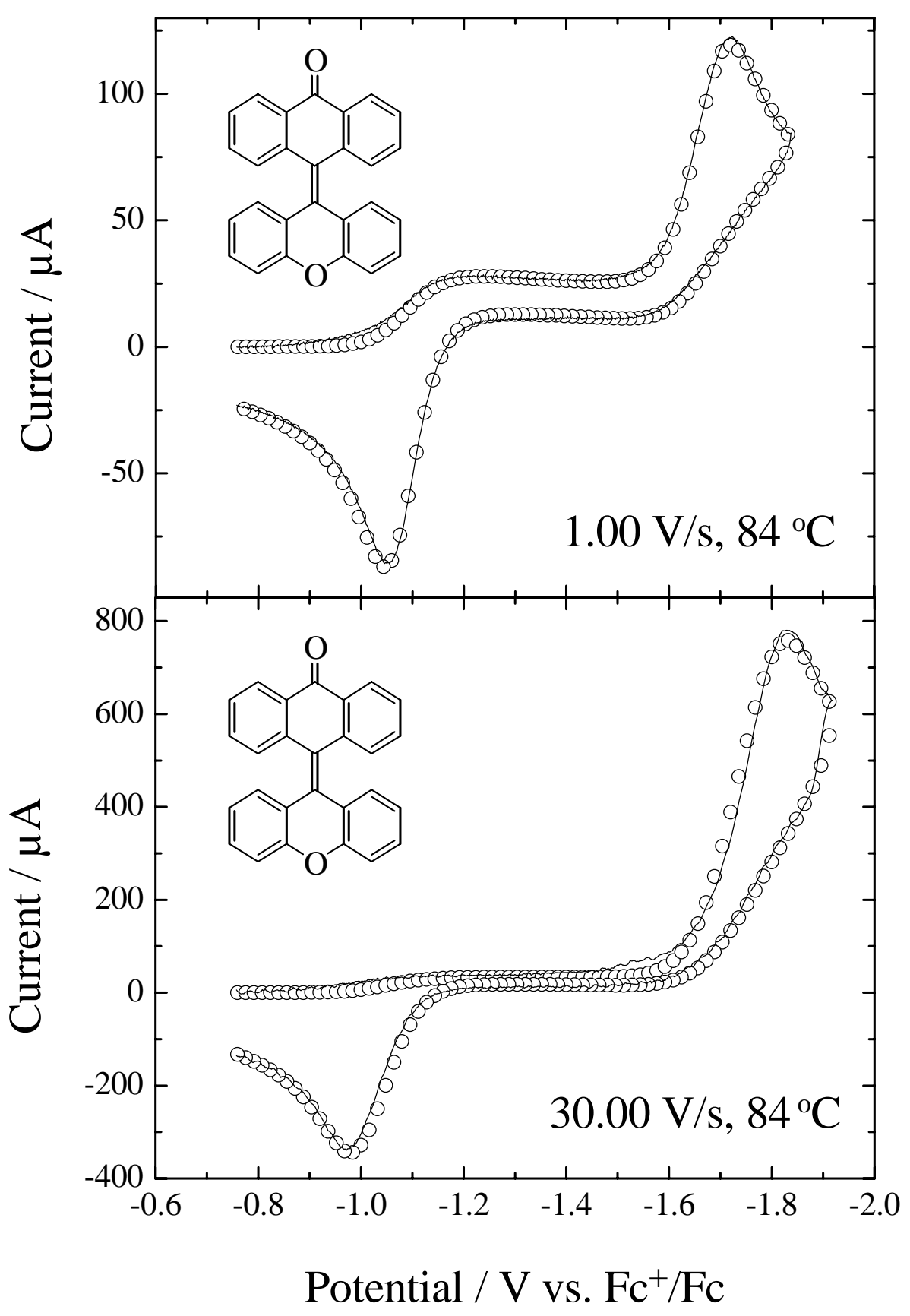

Figure S7 


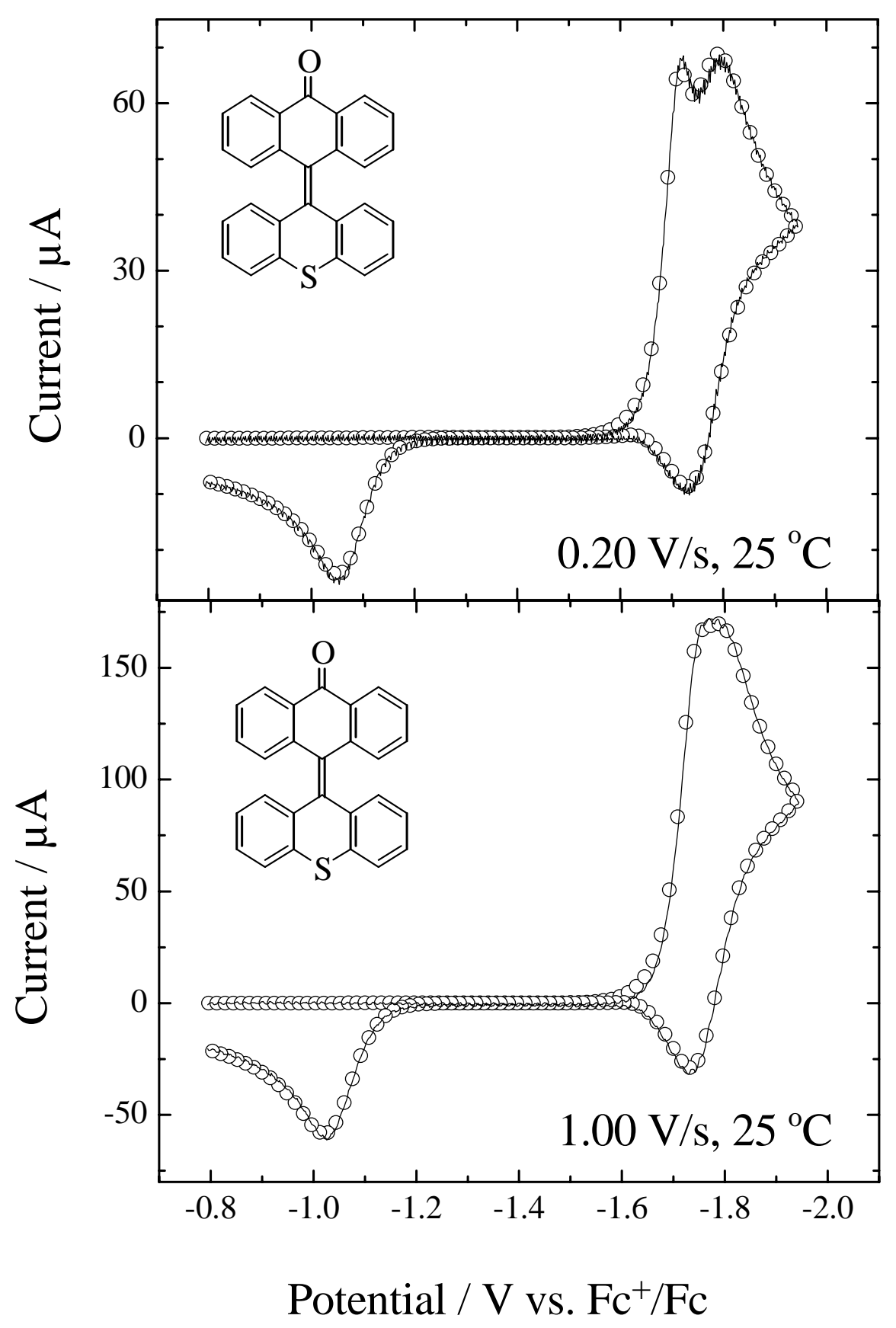

Figure S8 


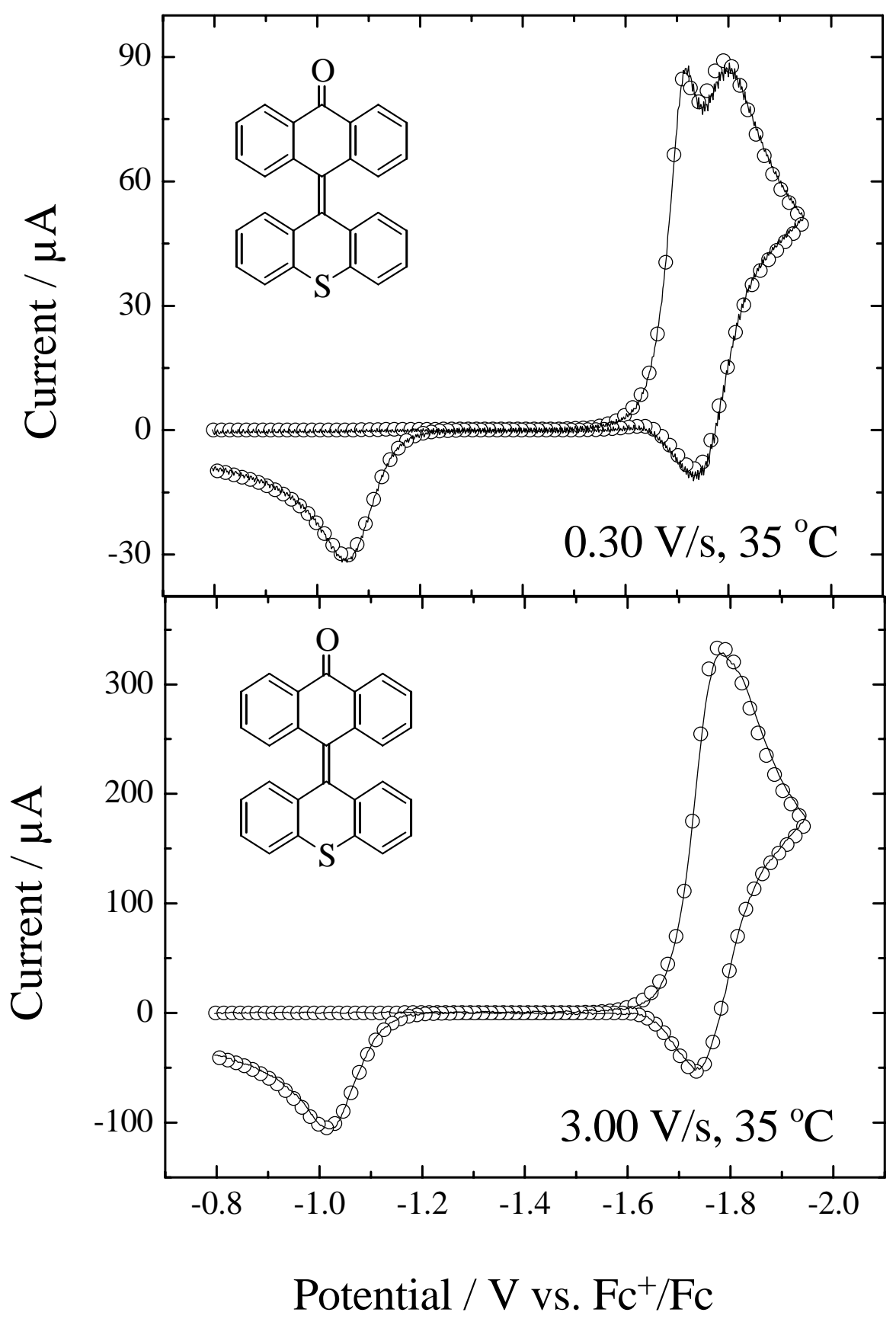

Figure S9 


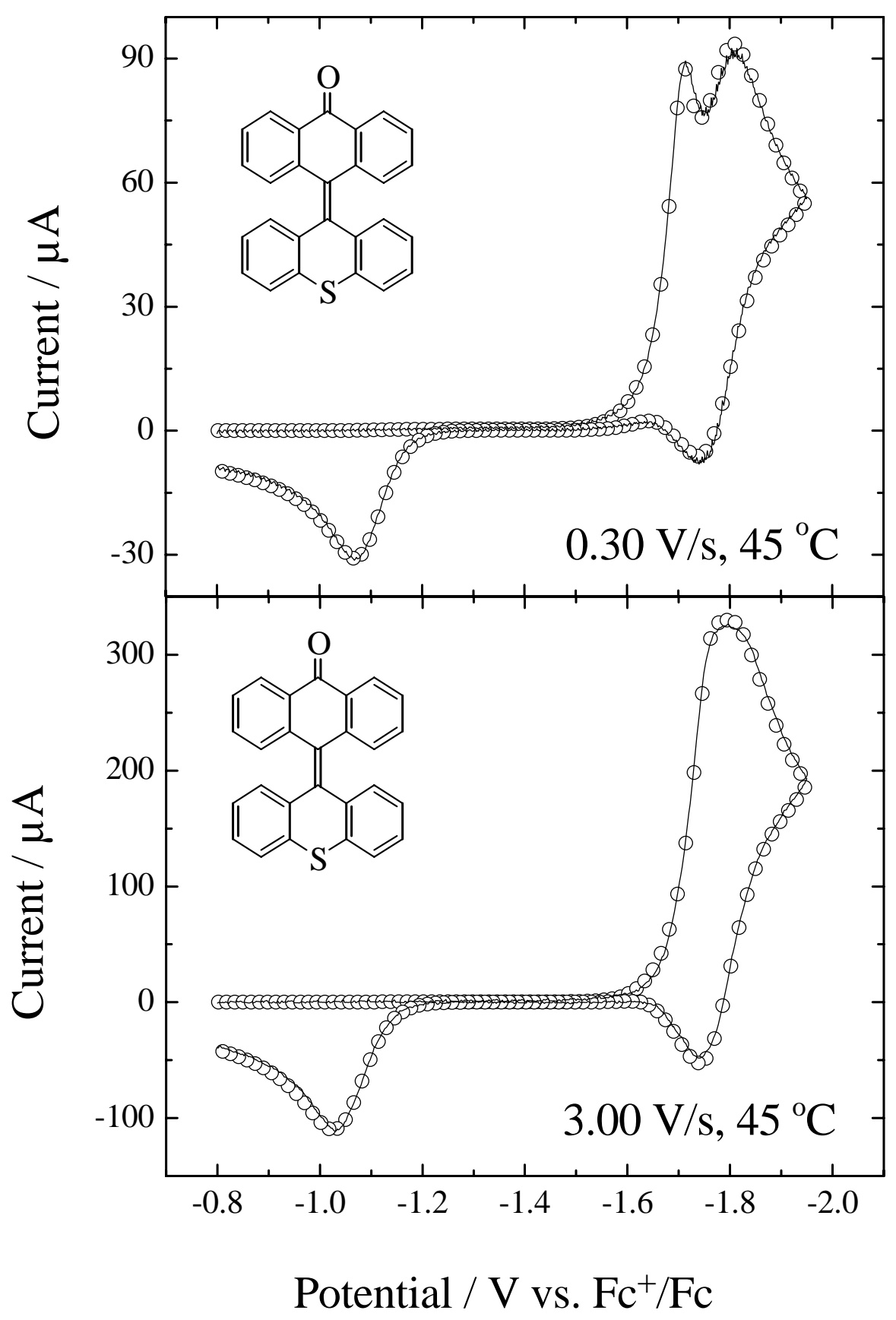

Figure S10 


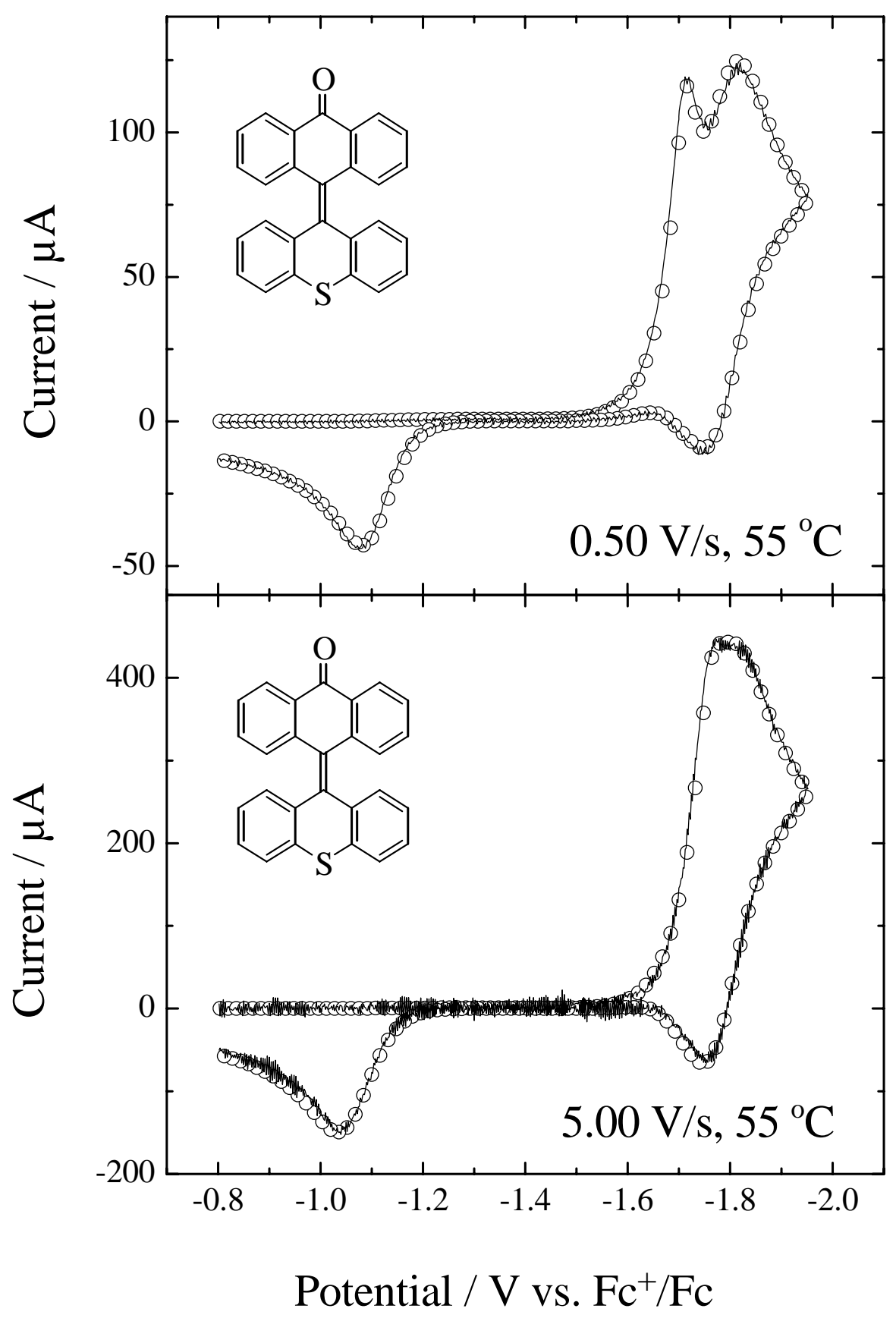

Figure S11 


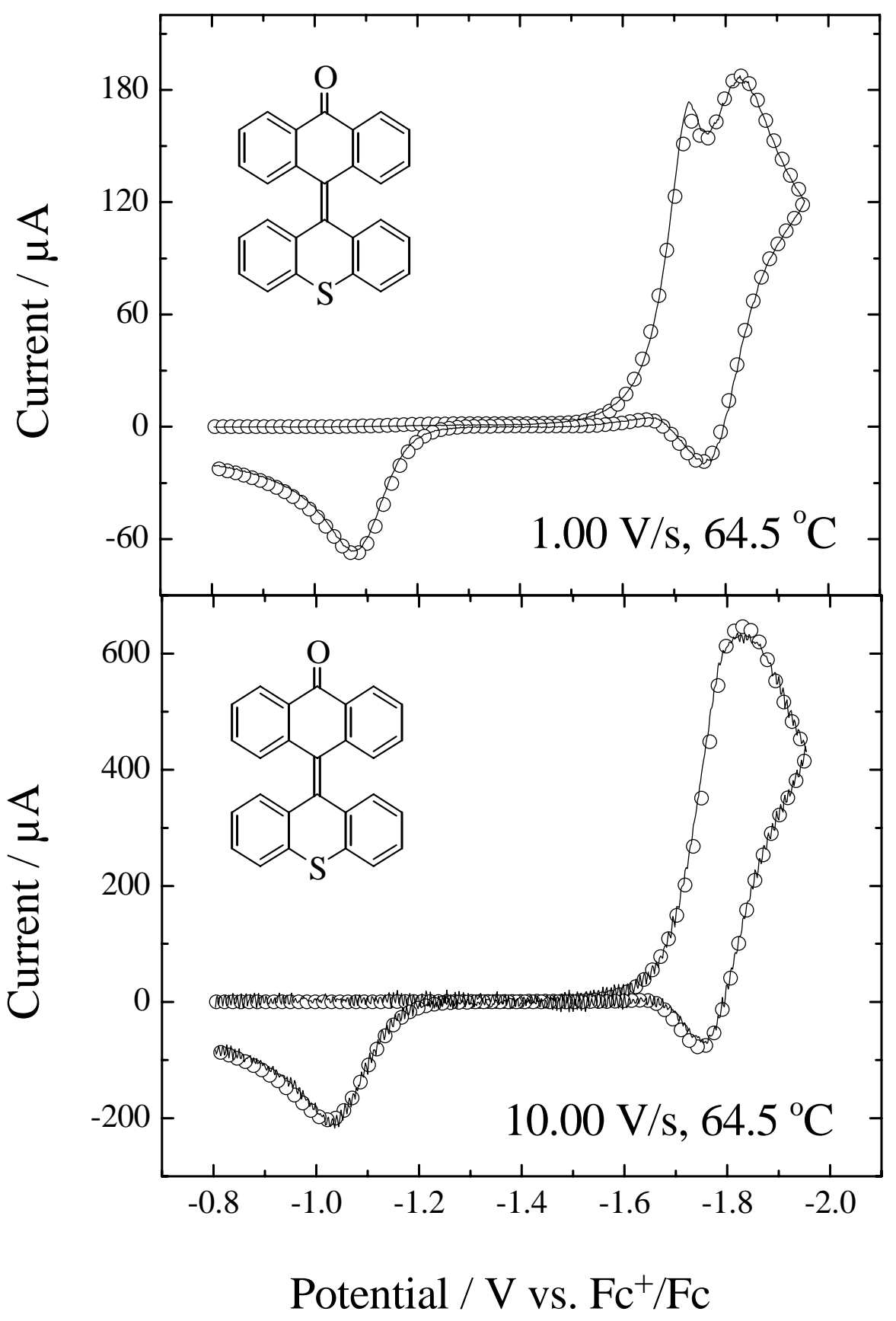

Figure S12 


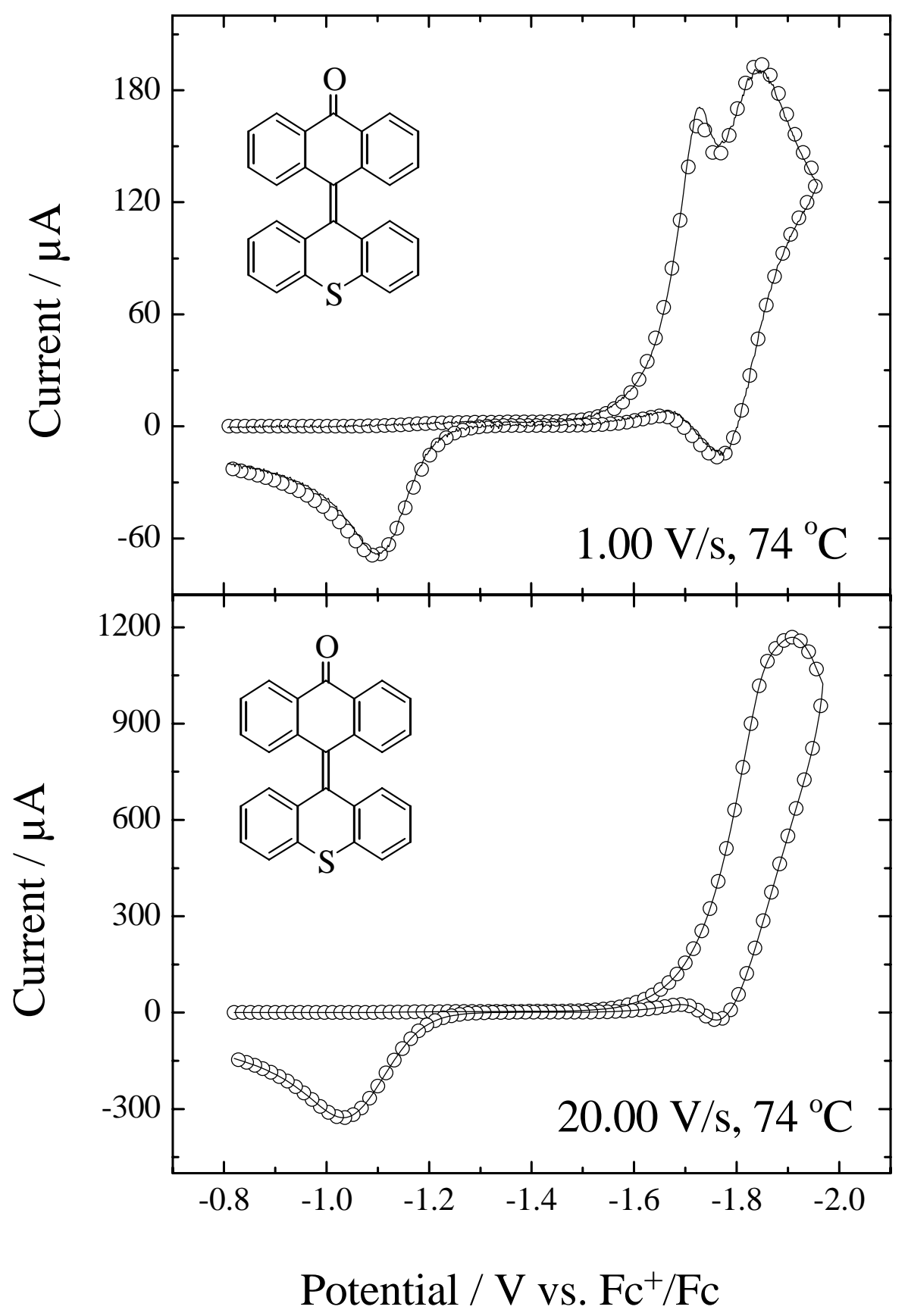

Figure S13 


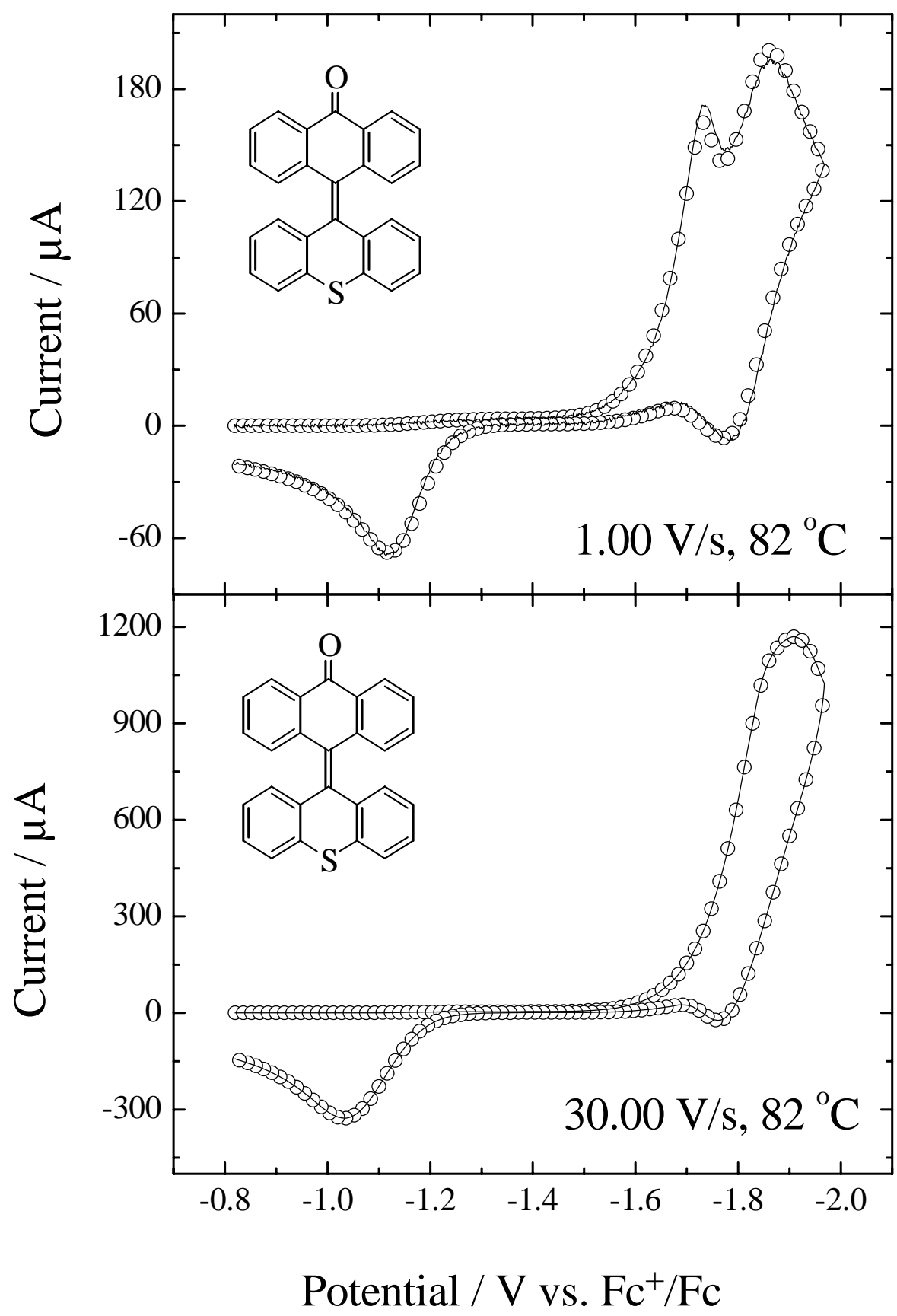

Figure S14 


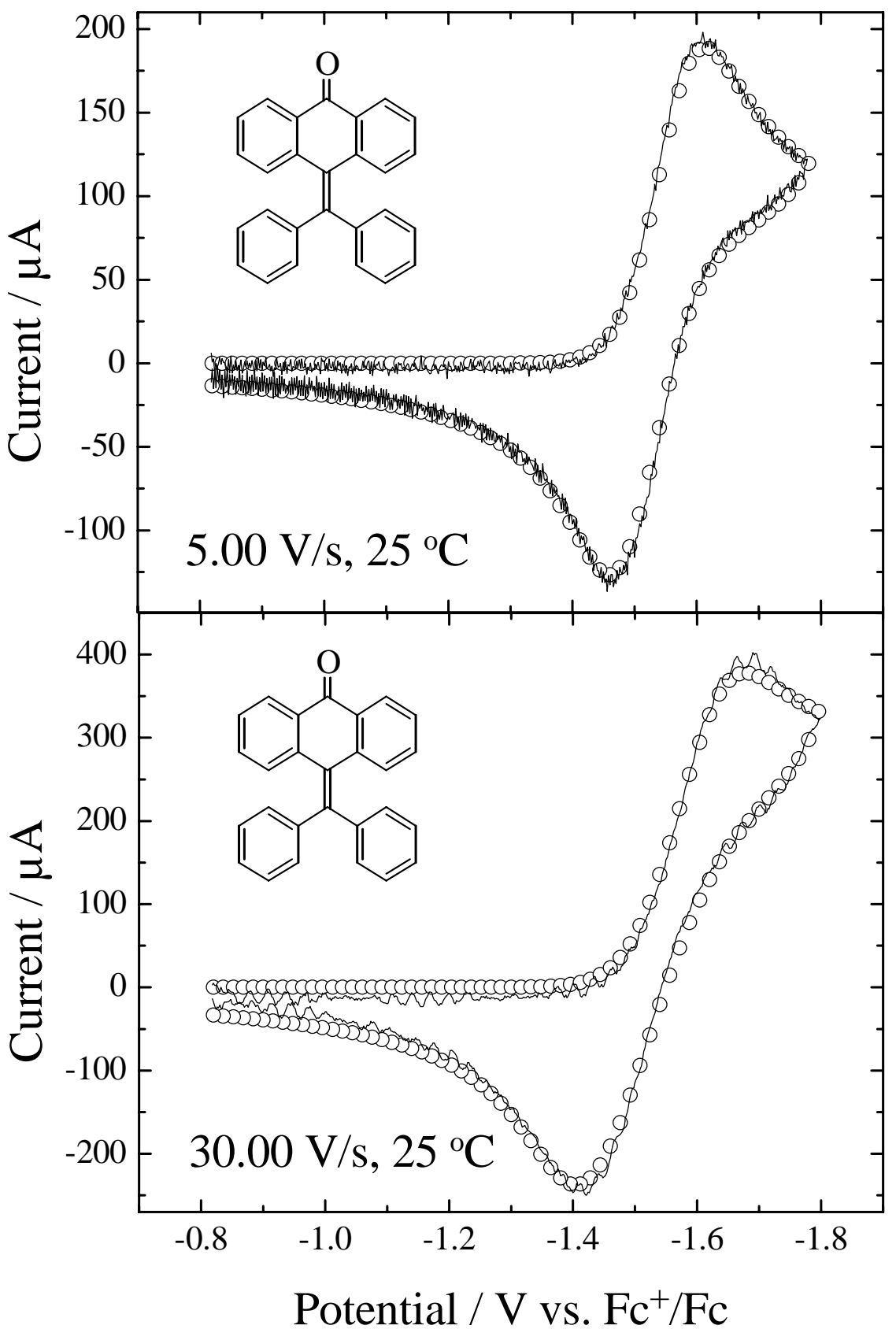

Figura S15 


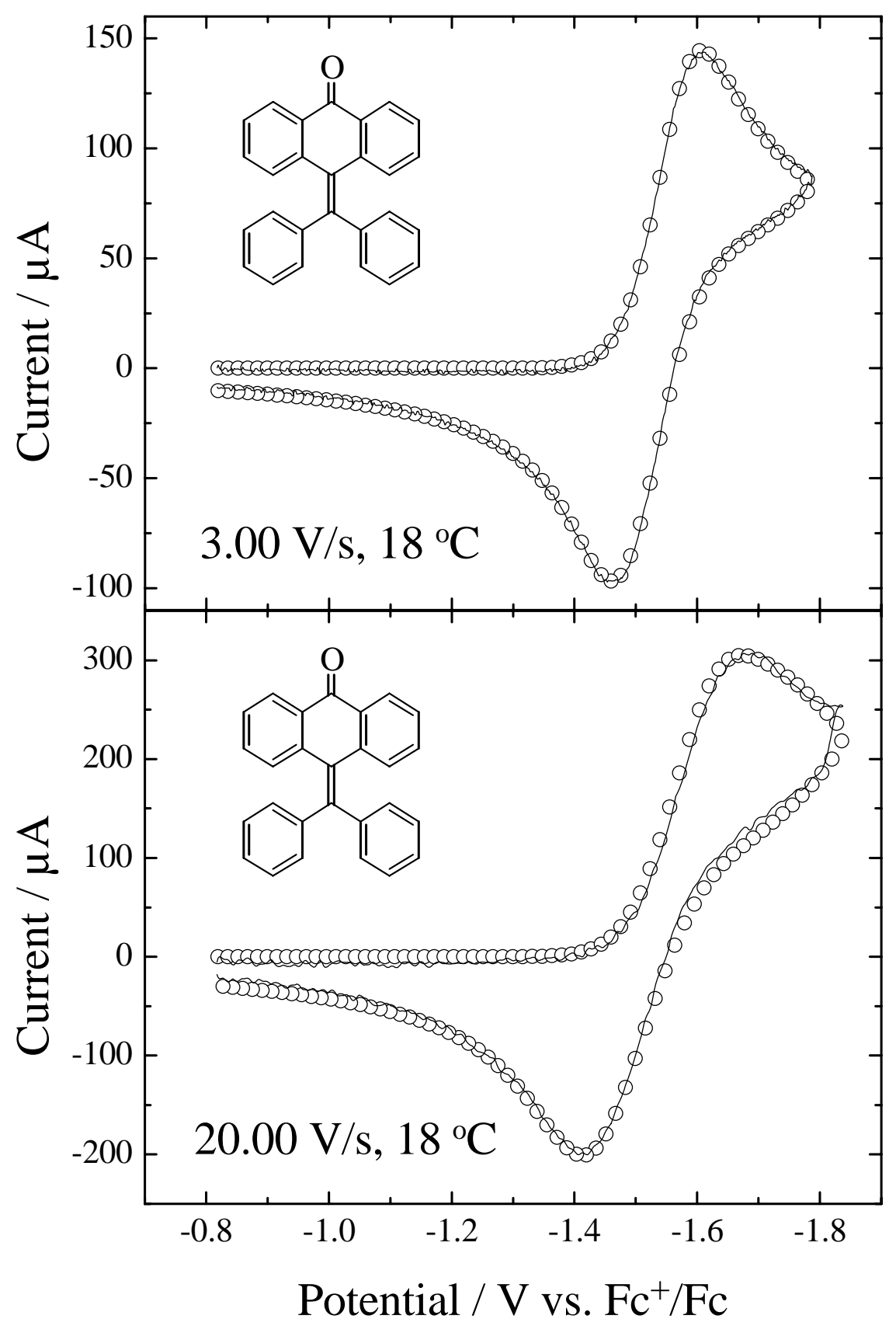

Figure S16 


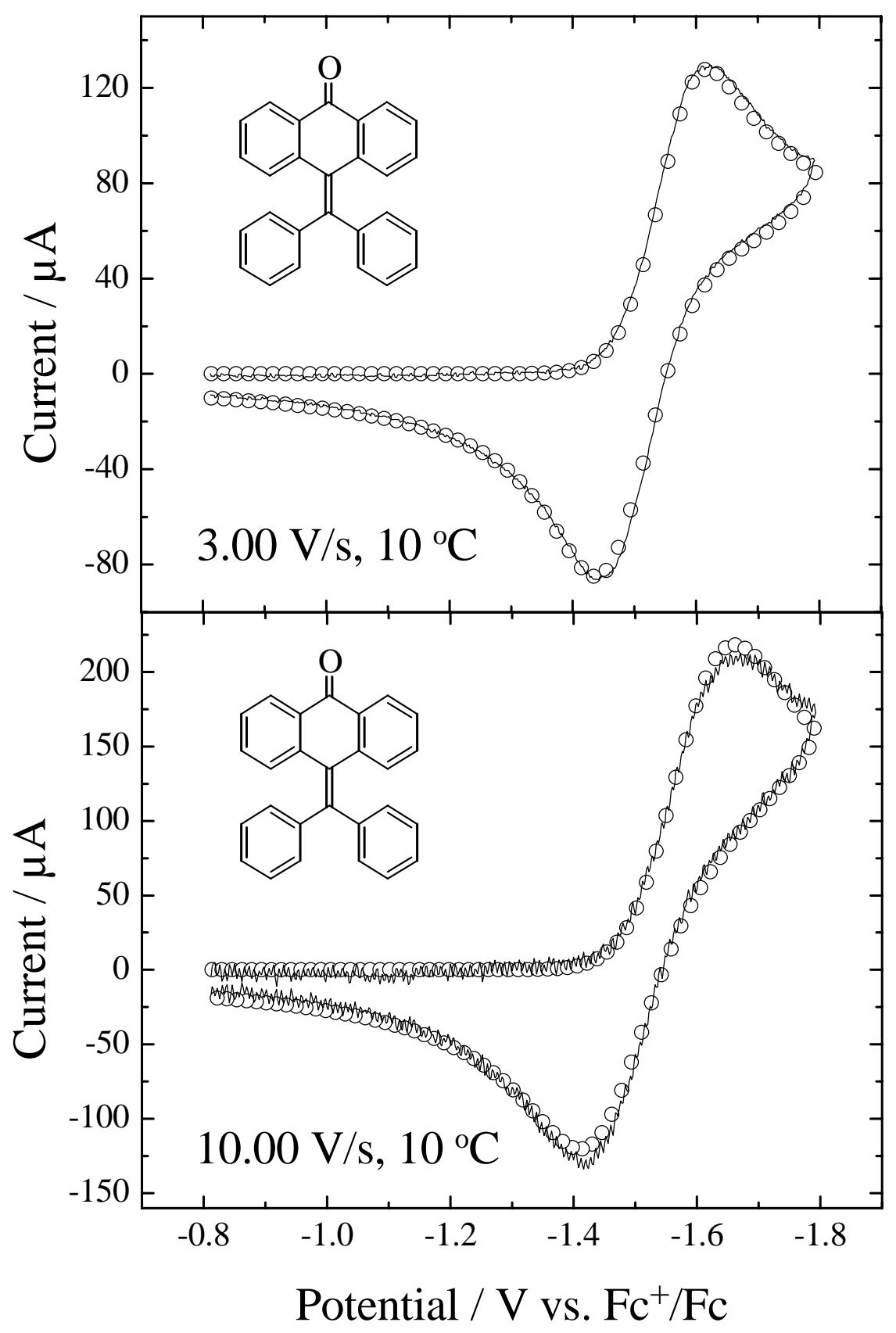

Figure S17 


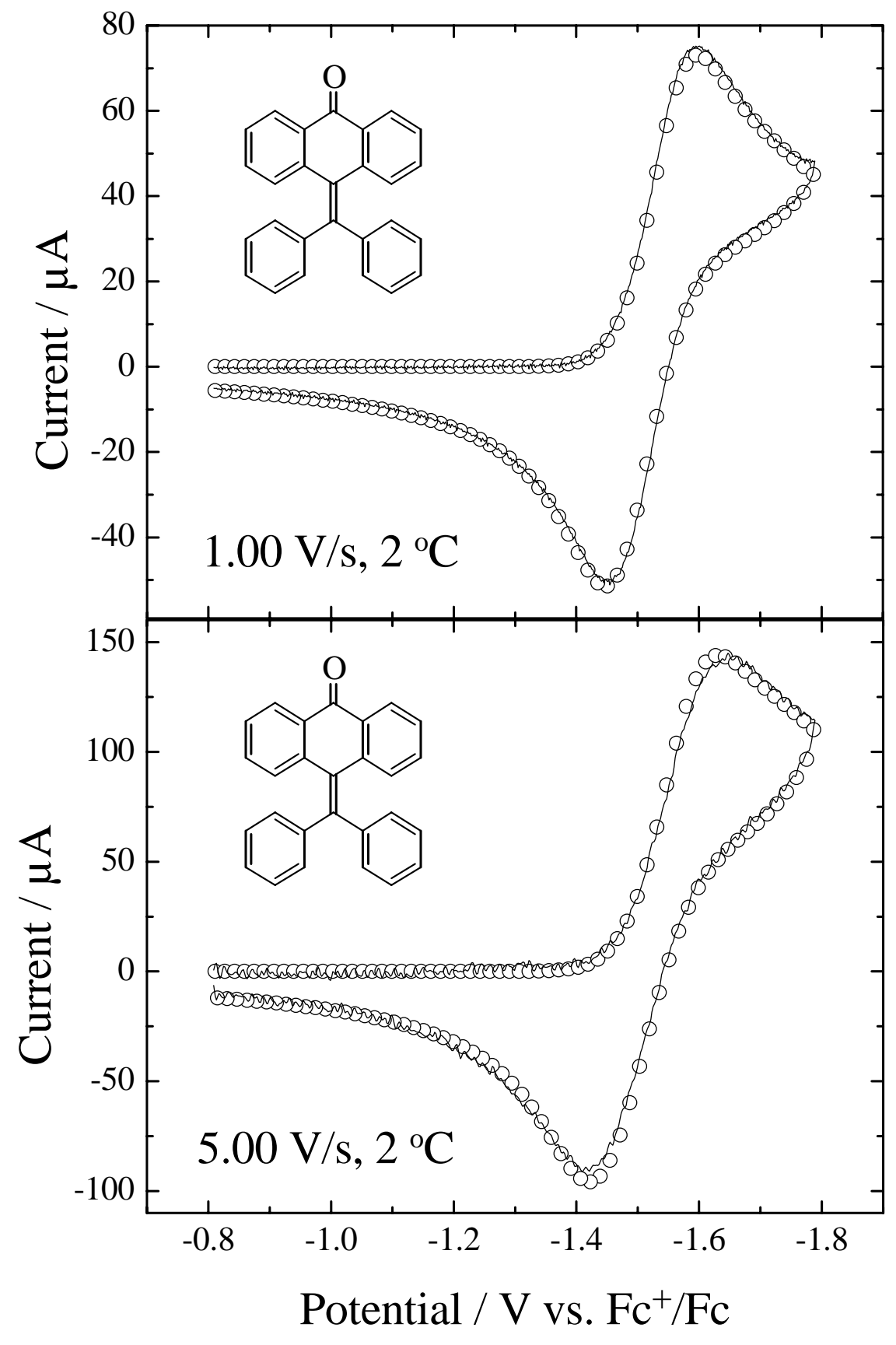

Figure S18 


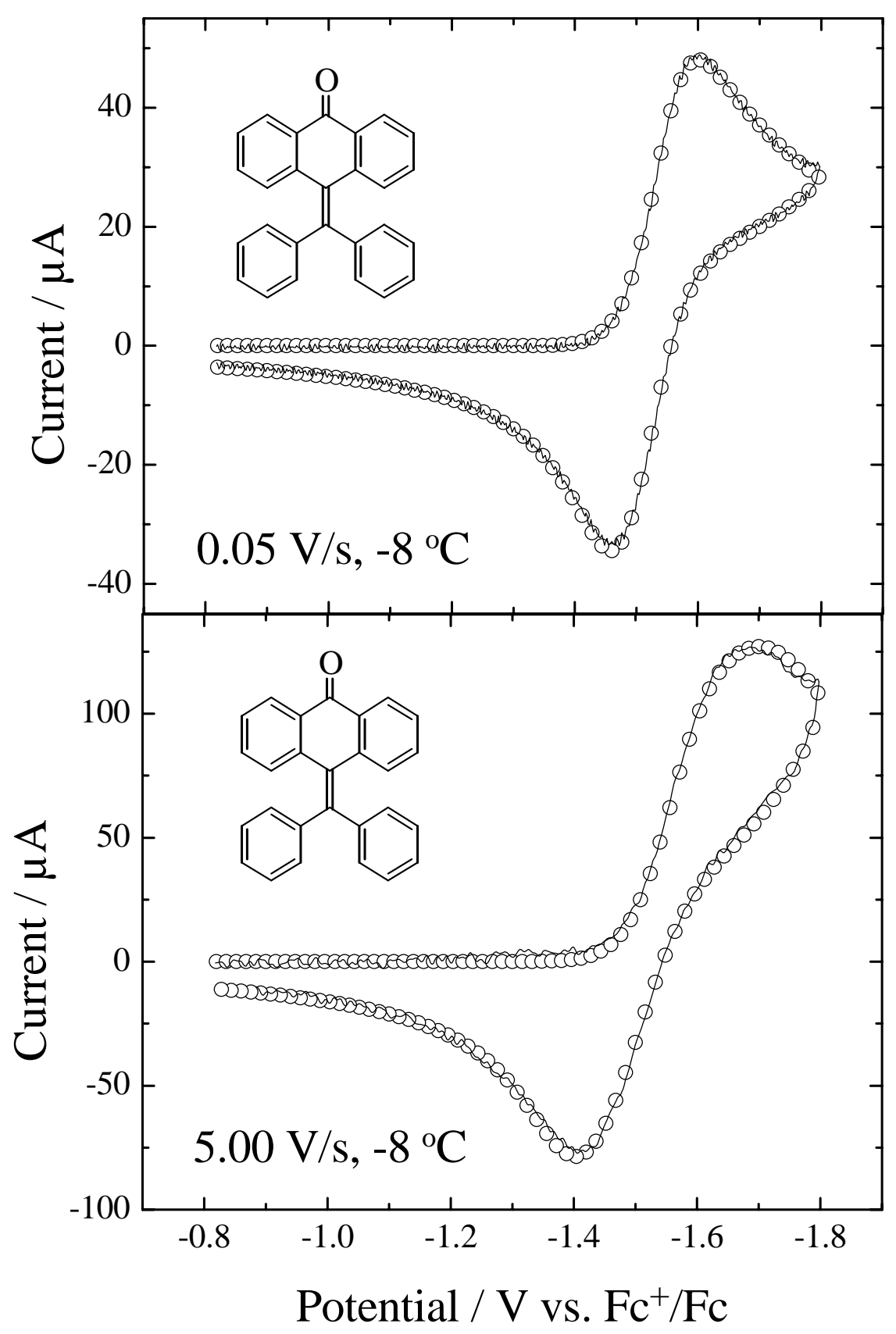

Figure S19 